MedieKultur | Journal of media and communication research | ISSN 1901-9726

Article - Theme section

\title{
Danske intellektuelle på Facebook - eksemplificeret ved Svend Brinkmann og Carsten Jensen
}

\section{Erik Svendsen}

MedieKultur 2018, 65, 54-75

Published by SMID | Society of Media researchers In Denmark | www.smid.dk

The online version of this text can be found open access at https://tidsskrift.dk/mediekultur

\begin{abstract}
The article analyses how two unique Danish intellectual voices, Professor Svend Brinkmann and writer Carsten Jensen, use Facebook as a platform. It argues, on the one hand, that Facebook offers direct access to the two intellectuals' followers and readers but on the other hand also creates communicative challenges. The article asks in particular whether Brinkmann and Jensen follow or depart from the communicative practices afforded by the platform. After an initial review of the literature about the public intellectual, the analysis of Brinkmann's and Jensen's use of Facebook shows how Brinkmann manages to invent new short forms which grant him extended public impact, whereas Jensen uses Facebook to extend his work as a polemist. Moreover, the analysis argues that both intellectuals perform a private self and position themselves vertically and authoritatively in relation to their followers. In addition, like most other Facebook users, they also promote themselves and their activities. Habermas once pointed to social media's ambivalences vis à vis the intellectual. The article's analysis substantiates this claim.
\end{abstract}

\section{Keywords}

den intellektuelle, meningsdanner, tæenketank, Facebook, selurepræesentation på Facebook, genrer på Facebook, Svend Brinkmann, Carsten Jensen. 


\section{Introduktion}

Hvad sker der med de intellektuelle, når de ikke sidder i et elfenbenstårn men må agere i en digital æra mærket af de sociale netværksmedier som Twitter og Facebook? Den sidste er ubetinget den kvantitativt største medieplatform, og det faktum er argumentet for, at jeg i det følgende vil fokusere på to markante danske intellektuelles kommunikative praksis på Facebook. Med afsæt i en tentativ bestemmelse af den intellektuelle som idealtypisk figur (sammenholdt med beslægtede stemmer som meningsdanneren), vil jeg forholde mig til to forskningsspørgsmål: 1) hvilke kommunikationsstrategier praktiserer intellektuelle på Facebook? og 2) hvordan er deres kommunikative performance sammenlignet med de dominerende kommunikationsformer på medieplatformen? Sigtet med artiklen er således ikke at give et generelt billede af, hvordan de sociale medier udgør en platform for debat, derimod at præcisere hvordan en afvigende minoritetsgruppe, in casu markante intellektuelle, håndterer udfordringen fra Facebook. Det skal understreges, at Facebook ikke er et sine qua non for de intellektuelle, snarere en ekstra mulighed for at komme i kontakt med læsere og andre interesserede. Forudsætningen er at det lykkes at kreere underfundige, kortere eller kontante former fremfor de elaborerende skriftlige formater, der kendetegner den intellektuelle. Det skal endvidere understreges, at jeg skelner mellem intellektuelle, der initierer eller aktivt indgår i en offentlig debat (i faglitteraturen rubriceret som "public intellectuals") og intellektuelle, der nyder kategoriseringen alene i kraft af deres akademiske kompetence (Melzer, 2003, pp. 3-14). Det er den første type artiklen fokuserer på, ikke de mange intellektuelle der foretrækker at kommunikere med fagfæller og begrænser deres dialogiske virke til institutionelle sammenhænge (Said, 1994, pp. 3-19; Baert, 2013, pp. 27-53). Der er utallige belæste mennesker, der er intellektuelt kompetente, men det gør dem ikke til 'public' intellektuelle.

Jeg fokuserer på, hvad "public" intellektuelle skriver om, hvordan de gør det, hvilke genrer de benytter, og hvordan de forvalter deres autoritet. Nedenfor angives nogle klassiske bestemmelser af den intellektuelle, men en absolut definition findes ikke (Collini, 2006, pp. 15-69; Etzioni, 2006, pp. 1-30; Misztal, 2007, pp. 13-38). Grænserne er flydende, hvorfor debattører og andre former for meningsdannere inkluderes. Har vi ikke mange "public" intellektuelle som i "de gode gamle dage" hvor Villy Sørensen inkarnerede den frie og uafhængige intellektuelle (Mannheim, 1929), har vi i dag konkurrerende kategorier, der er klar til at indtage den plads, som er blevet ledig efter, at den frie intellektuelle er blevet en raritet (et mønster der kendes fra Frankrig, USA og England, se fx Debray, 1981; Jacoby, 1987; Posner, 2003; Sand, 2016).

Artiklen rummer tre dele. I første del redegøres der dels for nogle af de mest basale bestemmelser af den intellektuelle (overfor meningsdannere), dels for de sociale mediers hovedkarakteristika, selvsagt med fokus på Facebook (og ikke fx Twitter, der primært bruges af journalister). Anden del er analysen af hvordan to vidt forskellige typer af intellektuelle, Svend Brinkmann og Carsten Jensen, agerer på Facebook, og i tredje del diskuteres analysens resultater. Brinkmann repræsenterer den professionelle, institutionsforankrede, 
integrerede intellektuelle, mens Jensen er den frie og uafhængige intellektuelle forfatter. En vigtig pointe er, at de intellektuelle på den ene side er konstitutionelt afvigende i forhold til det kommunikative regelsæt på Facebook, og hvordan disse undtagelser på den anden side også i et vist omfang følger de formidlingsstrategier, der dominerer medieplatformen. Det er imidlertid afgørende at understrege, at Facebook er en supplerende kontaktflade ligesom det må pointeres, at relativt mange prominente danske public intellektuelle ikke bruger Facebook, fordi medieplatformen ikke matcher den intellektuelles kommunikationsformer. Den intellektuelles primære scener finder vi i de klassiske massemedier (bogen, avisoffentligheden og radio-tv). Indtil videre. Også "public" intellektuelle lever i et interregnum, hvor populisme og antiintellektualisme er udtalt, men disse tendenser forbliver i det følgende blot en vigtig baggrund (Müller, 2016; Jensen, 2018).

\section{Meningsdannere og/ eller intellektuelle}

Ifølge faglitteraturen (fx Posner, 2003, pp. 17-41; Collini, 2006, pp. 45-68; Dahlgren, 2013, pp. 51-70) er det karakteristisk for intellektuelle, at de sætter en ny dagsorden - fx Villy Sørensen, der promoverede kontroversielle tanker bag velfærdsstaten (Sørensen, 1959). Meningsdannerne derimod lever af at følge med tiden, og de taler sjældent imod tidsånden, snarere spidsformulerer de den. Meningsdanneren har let ved at blive opportunist, den intellektuelle derimod sætter en ære i at kritisere de herskende meninger (Said, 1994; Melzer, 2003). Det er ingen tilfældighed, at essayet eksklusivt praktiseres af intellektuelle, idet genren netop er en fordomsfri undersøgelse af et område (Adorno, 1958). Essayet er ikke en akademisk disciplin; omvendt kræver den et intellektuelt overskud, som er en akademiker værdig. Genren implicerer research og viden men kalder ikke på det docerende. Meningsdanneren derimod har sin klare mening om sagerne, og ærindet er her polemisk, snarere end det er reflekterende. Det intellektuelle "luftmensch" (Posner, 2001, p. 33) ynder en teoretisk idedebat, og kan derfor fremstå verdensfjern, hvad en meningsdanner meget sjældent er (Posner, 2001, pp. 17-40). Den intellektuelle behøver ikke at være populær for at virke i medierne, mens meningsdanneren nyder mediernes bevågenhed, så længe vedkommende spidsformulerer tidens dominerende holdninger, der p.t. er liberale eller konservative.

Eksempler er præsten Katrine Lilleør, antropologen Dennis Nørmark, radioværten Mikkel Andersson, historikeren Michael Jalving og filosofparret Eva og Rune Toftegaard Selsing. Alene i kraft af deres uddannelsesbaggrund er det oplagt at taksere dem som public intellektuelle eller debattører, der har en eksplicit politisk agenda. De har alle mindst en medieplatform. Værdikonservative Lilleør og Rune Selsing har en blog på Berlingske, Jalving en blog på Jyllands-Posten, mens liberalisten Nørmark skriver opinionstekster i Politiken. Alle har en Facebook profil, og der er forskel på antallet af følgere. Lavest rangeret er Rune Toftegaard Selsing med 100, mens Mikkel Andersson topper med 7.200 følgere. 'De lave tal indicerer, at Facebook-profilen ikke kan matche bloggen som kommunikationsforum for meningsdannerne (Rettberg, 2014), og hvad angår gennemslagskraft i 
samfundsdebatten er hyppig optræden i massemedierne et sine qua non. Dennis Nørmark og Katrine Lilleør har flere bogudgivelser på deres CV, og litteraten, tidligere blogger på Berlingske og nu direktør for tænketanken Unitos, Kasper Støvring, har publiceret flere bøger, der placerer ham som en (national)konservativ intellektuel.

Ifølge faglitteraturen er den intellektuelle i kraft af sin outsiderstatus karakteriseret ved at være uforudsigelig (fx Jennings, 1997, pp. 1-24; Posner, 2003, pp. 17-40). Størsteparten af de nævnte meningsdannere har heroverfor et fikspunkt, nemlig den muslimske minoritetskultur der angiveligt truer nationalstaten. Man kan vanskeligt hævde, at en udtalt skepsis overfor den befolkningsgruppe er kontroversiel, snarere er den forankret i den aktuelle danske konsensuspolitik, hvilket er et argument for at placere disse debattører i gruppen af meningsdannere. En "public" intellektuel tilskrives traditionelt rollen som heterodoks, mens det at være kritisk overfor muslimer repræsenterer en konservativ, ortodoks position (Bourdieu, 1992, p. 44). På den anden side er den vedvarende harcelering over truslen om 'islamificering' et karakteristisk træk ved en bestemt intellektuel type, som Umberto Eco kategoriserer som den apokalyptiske (Eco, 1964). Den aktuelle danske samfundsdebat er mærket af apokalyptiske meningsdannere. Som Habermas (2008, p. 52) betoner, er uforudsigelighed imidlertid en intellektuel dyd. Det ligger også til intellektuelle at plædere for universelle værdier (Bourdieu, 1992, p. 140); det var denne fordring, som drev Georg Brandes til at være medunderskriver på Zolas kritik af den franske stats anklager med Dreyfus og som historisk er det fænomen, der første gang italesatte 'de intellektuelle' (Thing, 1993).

\section{Intellektuelle typer}

Georg Brandes var i selskab med forfattere og videnskabsmænd, der var dybt anfægtede over statens magtforvaltning. Fra starten opererede man således med flere varianter af den intellektuelle, nemlig mht. profession en skelnen mellem henholdsvis den anerkendte forfatter (Zola) og akademikeren, der qua sin autoritet har gennemslagskraft i offentligheden (Brandes) og mht. kompetence en skelnen mellem generalisten og specialisten (Dahlgren, 2012) - og alle typer optræder som Zolas støtter. Den historisk set 'oprindelige intellektuelle' taler for de samfundets svageste og advokerer for oplysningens ideologi, men der findes afgjort også intellektuelle, som opfatter oplysningstraditionen som en ideologisk modstander (fx Søren Krarup, Sørine Godtfredsen og Kasper Støvring). Uanset politisk og idémæssig orientering er det fælles for "public" intellektuelle, at deres budskab trænger igennem til en bred offentlighed. De er måske elitære men er også vedkommende for mange (generelt om de intellektuelle, se fx Eyerman, 1994; Said, 1994; Jennings, 1997; Jørgensen, 2002; Etzioni, 2006; Baert, 2013; Svendsen, 2016).

Italienske Antonio Gramsci (1929/1991) skelnede mellem de traditionelle og organiske intellektuelle. De første udmærkede sig ved i deres arbejde i (ud)dannelsessektoren i bredeste forstand (fra præst, lærer til jurist og embedsmand) at sikre reproduktionen 
af den herskende forståelse af det samfundsmæssige, mens de organiske blev knyttet til nye samfundsmæssige bevægelser ( $\mathrm{fx}$ bønder, arbejdere, feminister osv.), hvis stemme de gerne ville være. De traditionelle og professionelle intellektuelle vil være tilbøjelige til at være konservative, mens de organiske, så længe de befinder sig i en oppositionel position, plæderer for samfundsmæssige forandringer.

Selv om man gennemgår en lang akademisk uddannelse, er der ingen garanti for, at man bliver intellektuel. Det er ikke en beskyttet titel, og man har i dag svært ved at gøre karriere som intellektuel. Det er derimod en rolle, man kan påtage sig (Dahlgren, 2013). Det er historisk signifikant, hvor få kvinder der har virket som "public" intellektuelle, og Toril Moi (2008) dokumenterer, hvordan det intellektuelle felt har været et mandsdomineret domæne. Den enkle forklaring er at patriarkatets historie næsten konsekvent har ekskluderet mulighederne for, at kvinder har kunnet træde i karakter som offentlige intellektuelle. Den fordrer i bogstavelig og overført betydning "A Room of One's Own" (Woolf, 1928/ 1978). Der optræder kun få kvinder i de national-historiske fremstillinger af de intellektuelles kampe med tidsånden (fx Müller, 2000; Collini, 2006; Hansen, 2013; Sand, 2018).

Man kan diskutere om den professionaliserede akademiker, solidt forankret i sit ekspertområde, har mistet sin autonomi, eller om den intellektuelle tværtimod står stærkere i dag i kraft af at være beskyttet af et institutionelt skjold. Har den ansatte den samme frihed som den frie intellektuelle, og er det et problem, at det i dag er sværere at være generalist, mens det er lettere at bevare sin integritet ved kun at udtale sig som specialist? Collini (2006) forsvarer den professionelle intellektuelle, mens Jacoby (1987) og Furedi (2004) mener, at professionaliseringen underminerer den frie kritiske tanke. Eco (1964) lancerede kategorien "den integrerede intellektuelle", der som professionel arbejder inden for systemet ( $\mathrm{fx}$ universitetet og mediebranchen), uden at det betyder, at han alene reproducerer traditionelle værdier og giver køb på sin intellektuelle integritet. Den akademisk skolede og/ eller universitetsansatte intellektuelle, specialisten, er den anden anerkendte variant af den intellektuelle, der supplerer den frie intellektuelle (forfatter) type a la Zola eller Brandes. Informations nuværende redaktør Rune Lykkeberg er et eksempel på en integreret intellektuel.

Differentieringen mellem den frie og den professionelle, lønarbejdende intellektuelle udvikles hos Patrick Baert (Baert, 2013), der opererer med tre typer "public intellectual". Den første er den professionelle, som spiller det spil, som universitetet fordrer, dvs. skriver til en snæver fagkreds (peer review) og har klar institutionel forankring, samtidig med at denne specialist kan fungere i dele af en offentlighed båret af veluddannede borgere; et eksempel er politologen Ove Kaj Pedersen som med bemærkelsesværdig gennemslagskraft har lanceret konkurrencestaten som begreb. Baerts anden kategori er den intellektuelle autoritet, som eksklusivt knyttes til det suveræne individ, der nyder godt af en fornem uddannelse, som per definition placerer den intellektuelle i en vertikal ophøjet position. Baert bruger Jean-Paul Sartre som eksponent for denne kategori, og han 
indrømmer, at Sartre som type tilhører fortiden. Den tredje type kalder Baert for den indlejrede ("embedded") intellektuelle, der fornyer linjen tilbage til såvel den organiske intellektuelle som Ecos integrerede intellektuelle, men hvor det nye er, at interventionen i offentligheden primært sker for at sikre finansiering af store forskningsprojekter. Baert refererer her til folk fra tænketanke, og Anthony Giddens engagement i Tony Blairs Labourregeringen kan demonstrere, hvordan intellektuelle spiller en afgørende rolle i politiske omkalfatringsprocesser. Baert opfinder underkategorien "dialogiske intellektuelle", der udmærker sig ved i modsætning til Sartres vertikale intellektuelle at være tilstræbt horisontale og gå i dialog med borgere - både for at kvalificere egne synspunkter og vinde legitimitet. Tænketanke-intellektuelle er som type i vækst, også herhjemme hvor Denis Nørmark og Jacob Mchangama har rødder i Cepos, og de nationalkonservative teologer Katrine Winkel Holm og Sørine Godfredsen advokerer for synspunkter, som man finder i tidsskriftet Tidehverv. Tænketanke er reservater for dele af intelligentsiaen, men man må spørge om en sådan associering kan forenes med den intellektuelles moralske og politiske frihed. I det mindste bliver det svært at bevare den intellektuelles dristige tankegang, når tænketanken har en veldefineret politisk bias.

Tænketanke-intellektuelle er per definition embedded og talerør for specifikke økonomiske-værdimæssige og politiske interesser. Af samme grund hører det absolut til sjældenhederne, at en dansk politiker opfattes som intellektuel. Med en ideologisk forankring følger nødvendigvis en forudsigelig tænkning, en professionaliseret argumentation og fremstillingsform, der ikke altid matcher med den intellektuelle undersøgende refleksion. Til gengæld kan den uregerlige polemiske lyst udmærke den intellektuelle politiker (Habermas, 2008, p. 52). Konservative Per Stig Møller har publiceret litteraturvidenskabelige værker og matcher kategorien embedded intellektuel.

Fælles for politikeren og den intellektuelle er, at de ikke kan undgå at blive selvpromoverende, når de kommunikerer på de sociale medier. Forskellen mellem de to er imidlertid iøjnefaldende: Hvor politikeren per definition repræsenterer et veldefineret partiprogram, er den frie intellektuelle ikke bundet til en given ideologi. Politikeren brander sit parti og dets værdigrundlag, mens "public" intellectuals vil have en mere uafhængig tilgang til den givne problemstilling (og indirekte gøre opmærksom på sig selv).

Panorerer man hen over det aktuelle danske landskab befolket af meningsdannere og intellektuelle, er det slående, hvor få uafhængige "public" intellektuelle vi har. De færreste danske forfattere kan leve af deres bøger, og samtidig er avisernes betaling for artikler og kronikker blevet symbolsk. Langt de fleste er nødsaget til at finde andet (løs)arbejde, som sikrer en bare nogenlunde årsindtægt. Heller ikke på universitetet hænger stillingerne på træerne, og præmissen for en renlivet akademisk karriere mindsker overskuddet til at skrive tekster, rettet mod en bred offentlighed. Den slags giver sjældent akademisk credit. Omvendt er det evident, at forankring i den universitære verden er fundamentet for mange af de integrerede (Eco) og "public" intellectuals (Baert, 2013; Dahlgren, 2013) som har gennemslagskraft i den politiske og kulturelle offentlighed. 
Man kan nævne semiotik- og idehistorieprofessoren Frederik Stjernfelt, filosofprofessor Vincent Hendricks og sociolog-lektoren Rasmus Willig, som har deres respektive mærkesager (ytringsfrihed og ex-Jugoslavien, de sociale mediers boblekultur og konkurrencestaten og dens mange dysfunktionelle sider), men de har også en bredere profil og blander sig i forhold, der ligger udenfor deres veldefinerede ekspertområde. Den sidste fordring er afgørende for denne "public" intellektuel, for kriteriet adskiller den akademiske intellektuelle fra specialisten, der gerne optræder i offentligheden, men altid udtaler sig om sit snævre ekspertområde. Med reference til Sartres berømte fordring om at den intellektuelle "er én, der blander sig i noget, som ikke kommer ham ved" (Sartre, 1972, p. 25), får vi to typer af universitært forankrede intellektuelle: Generalisten der overskrider sit fagligt definerede felt, og specialisten der konsekvent taler ud fra sit veldefinerede fagområde og sjældent kommunikerer ud til en bredere offentlighed.

Professor i folkesundhed, Lene Koch, kunne være et eksempel på den forankrede ekspert, medieprofessoren Kirsten Drotner et andet og professor i statskundskab, Marlene Wind et tredje. I øvrigt skal man huske, at den intellektuelle akademikers intervention i offentligheden ikke er risikofri; der har flere gange været politisk røre, når Marlene Winds faglige udlægninger af EU er blevet lanceret i en bredere offentlighed. Det kan være kontroversielt at være ekspert.

Endnu en nuancering af den intellektuelle: Fred Turner og Christine Larson angiver (2015) en rigtig pointe, nemlig at den hidtidige forskning favoriserer den intellektuelle som litterær figur. Alternativt peger de på linje med Baert (2013) på entreprenante teknologiske eksperter og ingeniører, der indgår i kollektive samarbejder og på den måde overskrider den geni-individualisme, der kan knytte sig til den humanistiske og sociologiske orienterede forskning, men i en dansk kontekst mangler vi, at disse entreprenante typer træder ind i en bred offentlighed. Hvor mange af disse kollektivt arbejdende tekniske eksperter har inddraget offentligheden i en diskussion af de værdier og ideer, der dominerer de computerteknologiske innovationer?

\section{Facebook, intimitet og emotionel kapitalisme}

Flere af de ovennævnte lokale "public intellectuals" udmærker sig ved ikke at have en Facebook-profil (fx Stjernfelt, Hendricks, Lykkeberg, Pedersen eller fx forfatteren Suzanne Brøgger). Det indicerer at medieplatformen ikke nødvendigvis er et must for intellektuelle debattører. På den anden side har en fremtrædende integreret intellektuel som Jürgen Habermas (2008) plæderet for de sociale medier som et mulighedernes land, fordi internettet har øget mængden af informationer, samtidig med at flere går i dialog i den digitaliserede offentlighed. De intellektuelle har fået det "som fisk i vand", skriver Habermas, der imidlertid også bruger andre metaforer, der angiver problemer, nemlig at velsignelserne er blevet til "et kors", og at de intellektuelle risikerer at få "en overdosis". Nettets ekspansion og fragmentering giver rum for kritisk refleksion. Omvendt undermineres de intellektu- 
elles autoritative position af internettets uformelle karakter og dets horisontalisering: "The price for the welcome increase in egalitarianism due to the Internet is a decentering of the modes of access to unedited inputs. In this medium, the contributions of intellectuals can no longer constitute a focal point" (Habermas, 2008, p. 53).

Habermas tilføjer en anden anfægtelse: "the iconic turn from word to image" (ibid.), som på den ene side betyder, at medieintellektuelle bliver (lokale) celebrities, men det fordrer på den anden side, at de intellektuelle opfylder mediernes (visuelle) præmisser, hvis de vil fange en større læserskare. Mediekulturen sætter dermed den saglige diskurs under pres, samtidig med at horisontaliseringen indebærer en individualisering, hævder Habermas. På linje med fx Lambert, (2013, se også Lundby, 2008; Jensen, 2013; Marwick, 2013; Rettberg, 2014; Enli, 2015) pointeres, at de sociale netværksmedier accentuerer selfpromotion, hvilket udfordrer genreskel og de bedste argumenters gennemslagskraft: "The blurring of the boundaries between discourse and self-promotion leads to a loss of differentiation and to an assimilation of the roles which the old-fashioned intellectual had once to keep apart" (Habermas, 2008, p. 54). Med til at understøtte denne udvikling er "The Demotic Turn" (Turner, 2010), som har skærpet vilkårene for de intellektuelles ageren i det offentlige rum, hvor de er oppe imod reality-stjerner i den ene ende af spektret og i den anden ende borgerjournalistik, og alle kæmper om opmærksomhed.

Facebook er en konvergent teknologi, og det betyder bl.a., at alle brugere bliver målt på evnen til at mobilisere flere udtryk og tegnsystemer (poste fotos, brug af hyperlinks, at like, kommunikere med læserne osv.). Først og fremmest repræsenterer Facebook et (positivt) identitetsarbejde. Det gælder principielt også for firmaer, institutioner og organisationer. Brand eller selv-repræsentation - forskellen er minimal (Marwick, 2013).

Alex Lamberts bog (2013) er et studie i intimacy og dens mange former på Facebook, og heri betones hvordan performance ( $f x$ via emotionelle tilkendegivelser, brug af smileys og fotografier), sharing (Jenkins, 2013) og selvafsløringer er afgørende kommunikative kompetencer. Medieplatformen er forum for pleje af kollektive netværker, og på den måde udgør Facebook "et psykoterapeutisk miljø" (Turkle i Lambert, 2013, p. 13). Omvendt pointerer Lambert (og fx også Sørensen \& Larsen, 2013), at der er grænser for, hvor selvafslørende og intim man typisk kan være. Platformen rummer "sharing emotional disclosures" (Lambert, 2013, p. 10). Konfliktreducerende smalltalk og gensidig pleje af face value udgør den dominerende sociale omgangsform. Selskabelighed, forsigtig adfærd, og konsensus vinder på bekostning af dissensus; tavshedsspiralen er også blevet sigende for de sociale medier (Scott Sørensen, 2013; Hjarvard, 2018, p. 173). Alle vil gerne være populære, og det lykkes, hvis der balanceres mellem at være selvafslørende og kontrolleret, mellem at være bramfri og påpasselig i kommunikationen. Det konforme og kontroversielle skal gå op i en højere enhed. Mængden af følgere og venner er succeskriterium nummer et.

Sociologen Eva Illouz har lanceret forestillingen om den emotionelle kapitalisme (Illouz, 2007). Vel vidende at hun fokuserer på datingssider, spidsformulerer Illouz en 
tendens, der også sætter sig igennem på Facebook, nemlig betoningen af selvrepræsentationen koblet til en accentuering af inddragelse af det private (det smertelige i særdeleshed). At have mod til at italesætte den sårede personlighed giver anerkendelse og er medium for erhvervelse af emotionel kapital (empati, positiv forståelse af andre osv.). Fra glamour over et liv i fart og kontrol til mental sårbarhed: alt tæller så længe det giver likes. Anerkendelsens valuta hersker såvel på datingssider som på Facebook; friends indikerer den emotionelle kapitals betydning.

Med andre ord er det selskabelighed, spontanitet og selvafsløringer i subjektspecifikke doseringer, der udgør de globale forhåndsforventninger til kommunikation på Facebook (se også fx Ellison, 2011; Mendelson, 2011). Globale fordi heller ikke intellektuelle kan kommunikere uden at forholde sig til de disse dominerende diskurser. Spørgsmålet er om man kan finde et modsprog til den emotionelle kapitalisme.

\section{De synlige intellektuelle}

Jeg har valgt at følge to af landets mest populære "public" intellektuelle, Svend Brinkmann og Carsten Jensen, som de præsenterer sig på Facebook. De to forfatteres "Facebook" sider og medfølgende kommentarer samme sted er det empiriske materiale, som omfatter tidsrummet fra 1. september 2017 til 31. december 2017. I de 122 dage har Brinkmann postet 107 gange, mens Jensen har opdateret sin hjemmeside med diverse tekster 18 gange. Jensen har altså produceret knapt et opslag per uge, mens Brinkmann næsten har lavet et opslag per dag. Et afgørende argument for det valgte tidsrum er, at efteråret og julesalget er afgørende for bogbranchen, og i efteråret 20117 udgav Brinkmann en ny bog.

De to valgte repræsenterer to vidt forskellige former for "public" intellektuelle. Brinkmann er den akademiske ekspert, den integrerede "public" intellectual, der kommunikerer med en bred offentlighed, samtidig med at han gerne bruger Facebook til at gøre opmærksom på sine universitære meritter. Psykologiprofessoren blander sig i debatter, der ligger udenfor hans ekspertområde. Samtidig følger Brinkmann en ide: kritikken af konkurrencesamfundets dyrkelse af det omstillingsparate. Brinkmann træder ind på de sociale mediers scene med et akademisk CV, og dertil kommer, at han forinden havde været populær gæst i debatprogrammer på P1 og hans formidlingstalent blev manifest, da Brinkmann fik DRs Rosenkjær-pris i 2015.

Carsten Jensen er valgt af flere grunde. Han har langt flere følgere end andre forfattere ( $f x$ Hanne Vibeke Holst, Helle Helle, Kasper Colling Nielsen, Theis Ørntoft, Morten Pape, Pia Tafdrup og lb Michael for at angive spændvidden), og han poster flere tekster end kollegerne. En anden grund er at Jensens genremæssigt bredt favnende forfatterskab tegner konturerne af en fri intellektuel. Som en af de få har Carsten Jensen en profil som essayist, samtidig med at han kan optræde som polemiker ved siden af at udgive rejsebøger, journalistik og romaner. I modsætning til de meningsdannere, der er nævnt ovenfor, udmærker Jensen sig ved at have modtaget flere priser, der dokumenterer institutionel 
anerkendelse og symbolsk kapital. Jensen har fået Georg Brandes-prisen (1993), De Gyldne Laurbær (1996), Holberg-medaljen (1999), Danske Banks Litteraturpris (2007), ligesom han har været adjungeret professor i kulturanalyse på Syddansk Universitet. Også i udlandet har han høstet anerkendelse, blandt andet markeret med Olof Palme-prisen (2009).

Fælles for de to valgte er, at de kritiserer de herskende værdier, og at de har gennemslagskraft i offentligheden. Et andet fællestræk er at de trækker deres intellektuelle CV med sig ind på de sociale medier. En markant bogproduktion parret med hyppig optræden i forskellige sammenhænge i massemedierne øger den kulturelle og sociale kapital. Hverken Jensen eller Brinkmann er afhængige af gennemslagskraft på de sociale medier; Facebook tilbyder blot endnu en adgang til læserne og andre interesserede.

Der er markant forskel på, hvordan Svend Brinkmann og Carsten Jensen bruger Facebook, og de genrer de benytter sig af. Der er også forskel på antallet af følgere: Carsten Jensen havde den 31. december 201716.000 følgere, mens Svend Brinkmann havde 78.000 følgere. Til sammenligning havde Lars Løkke Rasmussen 193.000 følgere, tv-værten Signe Molde 16.800, aktivisten Emma Holten 16.000, kulturjournalisten Ditte Giese 6.500 og forfatteren Anne Lise Marstrand Jørgensen 1.550 følgere. Carsten Jensen har ikke en egentlig Facebook-profil, men man får adgang til forfatterens hjemmeside via Facebook. Brinkmann derimod har en officiel profil.

\section{Facebook - stedet for korte humoristiske kommentarer. Om Svend Brinkmann}

En af pointerne i Rettbergs Seeing Ourselves Through Technology (2014) er brugen af fotografiet og de muligheder for selvrepræsentation, som mediet implicerer. Tilsvarende betoner Lambert (2013), hvordan mediet er essentielt for brugernes selvrepræsentation. Autentisk identitet finder en genvej i det indeksikalske medium, og fotografiet siger meget mere end ord: "It is an abyssal user-generated photo archive of everyday life and signals the social dominance of photographic self-expression. Photographs are valued for how they can picture the self in social situations, thus implicity disclosing one's interpersonal relationships" (Lambert, 2013, p. 16). Det er på den baggrund, man skal se den globale vækst af brugere på Instagram; for mange er de visuelle tegn mere oplagte at bruge til selvfremstilling og til at dokumentere hvad og hvem man bruger tid på. Der er høj signalværdi i postede fotografier, herunder profilbilleder.

Brinkmanns visuelle fremtoning er en afvigelse fra reglen. Det er ikke et nærbillede af et ansigt, der situationsbevidst smiler til fotografen, derimod ser vi i total Brinkmann med det, man må formode er hans tre børn, siddende på jorden og med ryggen til en mur. ${ }^{3}$ Alle ser væk fra fotografen, som om de ikke ved, at de bliver fotograferet. Men den beskyttelse af "the private self" (Marshall, 2010, p. 44), som familiebilledet indicerer, modsiges af de fire små indsatte mindre fotografier, hvor Brinkmann poserer med forskellige hatte, hvoraf nej-hatten er den mest iøjnefaldende og samstemmende med Brinkmanns 
intellektuelle-debatbrand som den, der siger nej til det hedonistiske begær efter stadig nye objekter. Hvor det store familiefoto synes privat men også distanceret qua afstanden til de fire og deres bortvendte ansigter, er psykologen kommunikerende med sine følgere på de fire små billeder. Den bevidste selvrepræsentation er parodisk, legende. Svend Brinkmann fremstår visuelt som en selvironisk selvposerende, performance-parodierende debattør (med kæk cykelkasket).

Han poster med jævne mellemrum nye fotografier, men fælles for dem er at de er officielle - Brinkmann bliver interviewet på en scene, eller han modtager en pris. Vi får aldrig private fotos, aldrig snapshots af hvad Brinkmann spiser eller andet, som har rod $\mathrm{i}$ Facebooks intimacy-kultur.

Et andet afgørende signal er den bemærkning Brinkmann anfører i introduktionsboksen: "Bruger mest FB til korte humoristiske kommentarer". Det er professorens stilistiske og fremstillingsmæssige credo. Den er også en vigtig forklaring på Brinkmanns succes (på Facebook men også på andre medieplatforme). På flere måder er Brinkmann formfornyende på medieplatformens præmisser. På et punkt er han imidlertid også en ortodoks bruger, nemlig i evnen til konstant at gøre opmærksom på hvor og hvornår han er i massemedierne. Facebook er en selvspejlende reklamesøjle for den enkelte bruger. En indiskret måde at fremstille sig selv på på den mest favorable måde. Det gælder også den hyppigt selvreferentielle Brinkmann, der skriver den 8. september 2017: "Jeg vil givetvis opdatere en del om bogen i forbindelse med dens udgivelse nu på tirsdag. Heldigvis kan man bare scrolle forbi og gå glip, hvis det bliver for meget". På den ene side en indrømmelse til kritiske følgere, der er ved at få nok af selvpromoveringen; på den anden side skriver han i det lukkede (fan)forum, som profilen er, og det lykkes raffineret at citere bogens titel i den negerende sætning.

Svend Brinkmann har med stort held udviklet sine egne korte genrer, velegnede til den hastige reception Facebook brugerne praktiserer (April 2016 loggede Facebooks 1,23 milliarder regelmæssige brugere sig ind på deres side i gennemsnit 17 minutter hver dag (Taplin, 2017, p. 130)). løjnefaldende er således en tilbagevendende genre: en fødselsdagshilsen til en kunstner eller intellektuel, fx Heidegger den 26. september 2017 eller den 7.november 2017, hvor det lyder: "Tillykke med din 104. års fødselsdag, Albert Camus. Du lærte os, at livet er absurd. Jeg tror, du havde kommunalpolitik i tankerne". Den uventede aktualisering, sammenstødet mellem filosofisk indsigt og dansk politisk pragmatik er slående.

Brinkmanns tekster er baseret på en ikke udfoldet argumentation, på tankespring som følgeren selv må foretage. Det præger de selvopfundne lister, der sammenstiller størrelser, som ikke nødvendigvis er ækvivalente. Det hindrer ikke, at sammenkoblingerne kan skrive civilisationshistorie, som fx den 7. september 2017: "1500: Kan Guds eksistens bevises? / 1600: Kan vi opnå sikker viden? / 1700: Hvad er oplysning? / 1800: Hvornår kommer revolutionen? / 1900: Hvordan skal vi leve efter Guds død? / 2017: Hvornår begynder Vild med Dans?". Brinkmann bruger zeugma, og sammenstødet mellem de øvrige eksistenstunge fænomener og et tv-underholdningsprogram eksemplificerer en vittig samfundskritik. 
Den 18. december 2017 postes "Ordbog over det politiske sprog", der en alfabetiseret sidestilling mellem effektivitet, forbedring, innovation, modernisering, omlægning, omprioritering, optimering, reform, stramning, tilpasning og udvikling, der alle er lig med - nedskæring. Dagen efter bliver listen citeret i sin fulde længde i både Politiken og Jyllands-Posten. Lørdag d. 23. december 2017 kårer Politiken i øvrigt psykologiprofessoren til årets meningsdanner.

Ligestillingen i Brinkmanns korte eller længere lister giver et rytmisk flow. På den anden side er det næppe korrekt, at innovation $\mathrm{fx}$ er identisk med nedskæringer. Men $\mathrm{i}$ den øjeblikkelige læsning fungerer remsen optimalt. På den måde argumenterer Brinkmann ikke som en saglig intellektuel, men nok som en effektiv retoriker, der har en skarp sans for at udnytte tomme pladser og metaforiske koblinger. Teksterne har deres tomme pladser, der virker læserstimulerende, også fordi Brinkmann anvender klassiske humoristiske greb - udover at han trækker på solid kulturel kapital. Et eksempel (fra den 20. september 2017)

\author{
Mennesket stræber efter: \\ Platon: Det gode \\ Aristoteles: Lykken \\ Epikur: Velvære \\ Buddha: Ikke at stræbe \\ Machiavelli: Magt \\ Dewey: Vækst \\ Maslow: Selvaktualisering \\ Honneth: Anerkendelse \\ Mig: En tom indbakke.
}

Det er ikke den eneste gang Brinkmann selv dukker op som den sidste i en kæde, altid med en selvironisk attitude, der undskylder, at han dog kan figurere på en lang liste af prominente intellektuelle. Det er heller ikke sidste gang, professoren på en gang udtrykker ærgrelse over at være så populær og samtidig koket dokumenterer, hvor ombejlet han er.

Listeprincippet styrer også en tekst fra den 7. september 2017, der på daværende tidspunkt er en teaser til bogen Gå glip som udkom fem dage senere:
"Livets fem faser:
(1) Du imiterer de andre
(2) Du finder din egen vej
(3) Du gentager dig selv
(4) Du gentager dig selv
(5) Så har livet ikke flere faser". 
Igen finder man dobbeltgrebet: På den ene side er der historisk progression i listen, på den anden side er manglen på udvikling slående, hvilket samstemmer med Brinkmanns diktum om at stå fast og hellere gå glip af en hel masse, som ikke er værd at beskæftige sig med. Det er ingen tilfældighed, at Brinkmann i sine udfoldede tekster, herunder i den populære trilogi, gerne trækker på Søren Kierkegaard, den danske mester i indirekte meddelelsesformer (Kierkegaard, 1846/ 1982, p. 55ff). Gentagelsens dialektik synes at være en grundtanke hos psykologiprofessoren.

En anden tilbagevendende figur er antitesen, der understreger postmoderne overdrev. Et eksempel er post fra den 17. november 2017, hvor det med imperativ lyder: "Demokratiet lever - husk at stemme! Lad folkets røst lyde! \#VildMedDans". Demokratisk afstemning om det politiske glider ind i populærkultur-konkurrence; underholdning overlejrer den seriøse politik. Det er ikke den eneste gang populærkulturen er tvetydig hos Brinkmann. Ambivalens ligger til den intellektuelle figur: Brinkmann modsætter sig deltagelse i forbrugerkapitalismens udskejelser - og sender "min personlige shopper til at foretage mine indkøb". Den skrivende er selv en del af problemet - sådan principielt set.

Kulminationen på denne selvironiske praksis er en metakommentar fra den 18. november 2017, der kunne stå som motto for studier af de sociale medier: "Jeg er blevet godt og grundigt træt af Facebook og tager en tiltrængt pause. Facebook er en afhængighedsskabende, narcissismeunderstøttende og fremmedgørende teknologi, hvor borgere villigt leverer data, som multinationale selskaber bruger til målrettede reklamekampagner mod specifikke segmenter. Jeg hopper af - i hvert fald indtil kl. 14. Vi ses på den anden side".

Taplin (2017) og Foer (2018) dokumenterer det berettigede i kritikken af mediegiganten, men det forhindrer ikke den skrivende $i$ at indrømme, at heller ikke han kan leve uden medieplatformen. Selvironisk eller ej. Det er nemlig også mere end tydeligt, at Brinkmann aktivt bruger Facebook til at reklamere for sine mange gøremål, herunder ikke mindst selvfølgelig sit forfatterskab. Det er slående, hvordan han bruger nogle af sine længste tekster på at gå i rette med anmeldere, som har misforstået hans bøger. Indigneret indskærper han den 2. oktober 2017, at også de populære udgivelser udspringer af videnskabelige studier: "Jeg står til disposition, hvis nogen vil interviewe mig om diagnoser, sorg, psykologiens filosofi, etik og normativitet, kulturpsykologi eller kvalitativ forskning. Det er nemlig mine forskningsområder!" Det emfatiske udråbstegn, som Brinkmann sjældent bruger, er sigende for det selvforsvar, der er en profilering af hans professionelle, akademiske jeg.

Som sagt er Brinkmanns profil uvægerligt en reklamesøjle, og han kan finde på at gøre opmærksom på stillingsopslag fra hans eget institut (d. 16. oktober 2017, ansøgere kan endog få Brinkmann som chef). Det institutionaliserede bagland giver Brinkmann tyngde. Det er heller ikke tilfældigt, at Brinkmann har haft et program på P1, hvor han interviewer universitetskolleger, helt i DRs Jens Rosenkjærs folkeoplysende ånd. 
På Facebook reklamerer Brinkmann ikke bare for egne aktiviteter, han er samtidig repræsentant for universitetet som system. Dvs. en integreret intellektuel, der kan kunsten på samme tid at være ortodoks og heterodoks (Bourdieu, 1992). Det sidste, fordi han kritiserer flere tidstypiske træk, fx den ekspanderende diagnosticeringstrang og nyliberale fordringer om at være omstillingsparat (Brinkmann, 2014). Brinkmans brand er, at han udfordrer tidsånden. Men han er også ortodoks, fordi hans kritik af de alternative terapiformer, der nyder stor bevågenhed overalt, også i de højere lag i virksomhedskulturen, indirekte er et forsvar for den videnskabelige psykologi, som selvsamme Brinkmann er repræsentant for (fx Brinkmann, 2008, 2015). På den måde er han en ortodoks repræsentant for den akademiske kultur.

\section{Om Facebook - en genvej til polemik og kritik. Om Carsten Jensen}

Carsten Jensens profilbillede har en ganske anden karakter end Brinkmanns. Forfatteren er fotograferet i halvtotal i sit arbejdsværelse stående foran reoler pakket med bøger til alle sider. Fotografiet er taget med vidvinkel, så følelsen af at være omsluttet af bogkultur er massiv. En stige markerer, at man er nødt til at bruge den for at hente bøger på de øverste hylder. Scenen er ikonisk: her bydes man velkommen af en imødekommende intellektuel mand. Han er som sin baggrund. En hjemmeside bruges som regel til at præsentere the public self, sådan er det også i tilfældet Carsten Jensen (Marshall, 2010). Det er akkurat arbejdsværelset, der hvor der skrives tekster, arbejdes intellektuelt, vi får et kig ind i, ikke i forfatterens privatliv. Hvis man endelig vil liste noget privat ud af præsentationsbilledet, skulle det være det glade smil, der ikke korresponderer med hans image som skarp polemiker. Den private Carsten Jensen griner. ${ }^{4}$

De fotos man finder på forfatterens hjemmeside har alle en officiel karakter. Det kan være professionelle portrætfotos eller fotos, der viser forfatteren på arbejde, oftest som optrædende på en litterær scene. Der er hverken på den visuelle side eller på skrift tilnærmelse til et intimate private self.

En polemisk artikel fra den 20. september 2017, "Har demokratiet skåret halsen over på sig selv?", kan illustrere den måde Carsten Jensen transformerer det private til det almene, og samtidig er læserimødekommende, når han direkte indskriver et læsende, kollektivt "I" i teksten, dvs. en aktiv udnyttelse af sprogets konative funktion, som vil have modtagere til at reagere. Udgangspunktet er, at Carsten Jensen har været på hospitalet for at blive opereret i halsen. Der mødte han filminstruktøren Erik Clausen, der siger følgende: "Jeg er sikker på, at der er masser af mennesker, der gerne ville se dig med halsen skåret over, Carsten". "Synes du, at jeg skal lægge det ud på Facebook?" spurgte jeg. "Ja", sagde Clausen. Det gør jeg nu ikke alligevel. Men nu ved I, hvorfor jeg i de her dage er så optaget af overskårne halse". Det angrebne stemmebånd konverteres til en moralsk opfordring til at tale imod tidens populisme, der aktuelt har manifesteret sig i valget i Tyskland. Via en analogisk tankegang kobler forfatteren mellem sin egen syge hals - og nødvendigheden af at bruge 
sin stemme. Det hedder i udgangen, der indrammer tekstens politiske problemstilling: "Men opfører tyske politikere sig som flertallet på Christiansborg, så ender de i stedet med at skære stemmebåndet over på sig selv, og så mister demokratiet sine vigtigste forsvarere i Europa. Tavshed er altid demokratiets værste fjende. Pas godt på dit stemmebånd".

Det er bemærkelsesværdigt, at Jensen har lagt flere artikler op på sin hjemmeside, der falder i forskellige genrer. Der er en hyldest til Kirsten Thorup (den 2. november 2017) og en artikel om Johannes V. Jensen (den 8. oktober 2017), der er Jensens efterskrift til en tysk oversættelse af Himmerlandshistorier. Der er et essay om vækstfanatisme, der også publiceres i Politiken (den 1. oktober 2017). De øvrige artikler er polemik, som (gen)trykkes i dagspressen. Overvægten af polemik peger på, at Jensen primært bruger Facebook til at markere sig som polemiker. Som hos Brinkmann prioriteres de korte, slagkraftige formater.

Også Carsten Jensen bruger sin hjemmeside og Facebook til at reklamere for arrangementer, han er involveret i. Selviscenesættelsen er evident og uomgængelig. For en intellektuel, der vil fremme diskussion om det almene, er dette væsenstræk ved Facebook en vedvarende udfordring.

Hvor Svend Brinkmann har flair for den indirekte meddelelse, er det evident, at polemikeren Carsten Jensen benytter sig af den direkte meddelelse. Han poster spiddende tekster, der kommunikerer direkte til læseren. Det gør Jensen til en figur, læserne enten hader eller elsker (Kock, 2018; Mercier, 2018). Den 25. november 2017 linker Carsten Jensen til artiklen, "Tænk at være småtte. Mishandlingen begynder i sproget", der bringes i Fyns Stiftstidende, og den kan tjene som eksempel på, hvordan nogle grundkomponenter hos den intellektuelle fungerer i polemisk-analytisk praksis (teksten indgår også i Jensen 2018, p. 56). To oplagte greb er på spil, nemlig for det første en udtalt sympati med samfundets svageste, her i form af indvandrere og de mennesker som havde den laveste placering i hierarkiet på Zentropa og derfor blev chikaneret. Edward Said betoner således i sine forelæsninger om den intellektuelle, hvordan figuren gerne tager parti for de marginaliserede og taberne (Said, 1994). For det andet baserer Jensen sin analyse af opfindelsen 'småtte' på en sproglig ideologikritik. Magten ligger i diskursen, Janteloven taler igennem sproget - og den ekskluderer. Jensens moralske fundament er et universalistisk menneskesyn, som tit er udtalt hos intellektuelle.

David Marshall (2010) taler om, at de sociale medier appellerer til (selv)præsentationen, mens de traditionelle massemedier snarere markerer en repræsentation. De to analyseeksempler demonstrerer, at det selv-referentielle og selvpromoverende ligger i Facebooks DNA. På den anden side forsøger de to intellektuelle konstant at trække repræsentationen af en verden udenfor internettet ind i deres virke på Facebook. Og de negligerer en af Facebooks selskabelige grundregler: Smalltalk er nemlig ekskluderet hos de to. 


\section{Diskussion: "Status Update" vs. "The Existentialist Moment"}

Mellemrubrikken er titlen på to bøger skrevet af henholdsvis Alice E. Marwick (2013) og Patrick Baert (2015), som jeg har læst i forbindelse med mit studie af de intellektuelle. Titlerne angiver, hvor langt der er mellem på den ene side de sociale mediers kerneydelse: at være medium for det private, at være en mulighed for den enkelte til at kommunikere med andre (gerne om det nære liv (the intimate self)) og på den anden side den filosofiske dimension, der knytter sig til intellektuel virksomhed. På den ene side har vi en horisontal og egalitær bestræbelse, der ligger som en teknologisk (og ideologisk) mulighed i og med de sociale netværksmedier, på den anden side en vertikal og elitær position, som den bedrevidende intellektuelle indtager (selv den organiske der låner sin stemme til nye bevægelser, som ønsker mere indflydelse). De to peger i hver sin retning.

Jeg har henvist til Sven Brinkmanns Facebook-post fra den 18. december 2017, "Ordbog over det politiske sprog", der efterfølgende blev gengivet i avismedierne. Dialektikken mellem de gamle og nye medier er, hvad angår de intellektuelle, afgørende: Et fænomen som Svend Brinkmann bliver et navn i den brede offentlighed, når massemedierne promoverer ham, og bogen Stå fast (2014) er i den sammenhæng helt essentiel. Uden den ville Brinkmann aldrig blive citeret i modemagasinet Vogue. Hvad angår den intellektuelle skal der foreligge et "CV", der giver credit, og denne anerkendelse er præmissen for at agere på de sociale medier (Dahlgren 2013). Indtil videre er det umuligt at finde en intellektuel, der har opnået denne status udelukkende ved at have slået sine folder på de sociale medier. Det afgørende er derfor, apropos Habermas, ikke om men hvordan de intellektuelle kan håndtere de udfordringer, som de sociale medier, in casu Facebook, repræsenterer.

Det er åbenbart, at såvel Jensen som Brinkmann er bevidste om den særlige kommunikationssituation, som knytter sig til Facebook. De bruger korte formater men bryder med medieplatformens "logik" ved blot at promovere et public self. Modsat reglen på Facebook bliver der ikke trukket veksler på den intimacy, som Lambert ser som den afgørende faktor på medieplatformen. Heller ikke Marshalls transgressive intimate self kan på noget tidspunkt forbindes med de to intellektuelle (Marshall, 2010, p. 45). Der er intet personligt grænseoverskridende eller ekshibitionistisk over den måde, de to forvalter deres Facebookprofil på. Deres statusopdateringer har et strejf af det private, men det er vel at mærke en privathed, der entydigt hænger sammen med promovering af deres virke i kulturoffentligheden. Hverken Jensen eller Brinkmann satser på en emotionel kapital. De repræsenterer på klassisk intellektuel vis ideer, og de appellerer til refleksioner over det fælles almene.

Det skred man finder i fx den litterære autofiktion mellem det private og fiktionære, det biografiske cirkus som Jon Helt Haarder reflekterer over i Performativ biografisme (2014), finder man ikke hos de to intellektuelle, denne analyse er baseret på - og i øvrigt heller ikke hos andre markante samtidige danske intellektuelle. På Facebook leger man ikke med identiteten, man promoverer derimod de salgbare sider af identiteten og the public self. 
Reglen for kommunikation på Facebook er smalltalk og gerne respons på andres kommentarer, men den fordring lever hverken Brinkmann eller Jensen op til. På den måde indtager de begge en autoritetsposition, og relationen til følgerne er imødekommende, men fundamental set asymmetrisk. Hverken Brinkmann eller Jensen indbyder læserne til at blive produsers i Bruns' forstand (Bruns, 2008). Ærindet er ikke at etablere eller pleje venskaber, hvad der ellers ligger til medieplatformens typiske bruger (Lambert, 2013).

Larry Friedlander gør opmærksom på, at forfatterautoriteten er vigende i web 2.0 kulturen (Friedlander, 2008, p. 180). Analysen af de to intellektuelle viser, at det er en sandhed med modifikationer - måske vel at mærke når vi har at gøre med mennesker, der qua deres kulturelle habitus kan placeres i en vertikalt hierarkiseret position, hvorfra der kommunikeres demokratiske holdninger til de mange følgere. De to dokumenterer konstant deres autoritet; omvendt er det tankevækkende, at de genrer, de anvender i Facebooksammenhæng, ikke er unikke for den intellektuelle, snarere er de knappe tekstformer velegnede til en hurtig reception.

Analysen peger således på et paradoks: Den intellektuelle kan få mange følgere på Facebook, men vel at mærke ved at satse på det polemiske talent (der selvsagt ikke er en eksklusiv form, alene knyttet til den intellektuelle) og ved at opfinde nye komprimerede fremstillingsformer, som er særligt velegnede til medieplatformen.

Begge skribenter er disciplinerede og partiske men aldrig så meget i affekt, at syntaksen bryder sammen. Begge trækker på solid viden og på den måde er deres public self forankret i en faglighed, der konverteres til samfundsengagement. Til gengæld går de sjældent i dialog med deres følgere. Også her er de afvigende fra den gængse Facebookbruger (Lundby, 2008; Lambert, 2013).

Brinkmann har i kraft af sin lyst til at performe en bemærkelsesværdig dobbeltstrategi. Brugen af fotografier med sjove nej-hatte og humoristiske opslag peger i retning af det legende. Hvis han en sjælden gang poster et foto, der ligner et privatfoto, bliver det brugt til tvetydigt at positionere Brinkmanns status og decimere selvsamme via den afløsende billedtekst. I en post d 17. oktober 2017 ser vi Brinkmann sidde på en gravsten, og teksten lyder: "Her hviler kendt samfundsforsker. Lige ved siden af Pierre Bourdieus grav/ \#onkelhumor". Joken demonstrerer stilistisk flair, for det dobbelttydige i verbet 'hviler' (død eller slappe af) er pointen, og qua den forskudte selvkarakteristik - psykologiprofessoren forvandles til samfundsforsker - markerer Brinkmann en intellektuel ambition: Brinkmanns interventioner manifesterer trangen til at udvide fagekspertisen (psykologi, filosofi) til samfundsforskning.

For de intellektuelle drejer kommunikation på Facebook sig ikke om selvrealisering, snarere om at gøre omverdenen opmærksom på en lang række samfundsmæssige problemer. Sprogets referentielle funktion er derfor central, mens den fatiske funktion er underbetonet (Scott Sørensen, 2013). Det er ikke selskabeligheden, der er vigtig, det er sagen. Forskellen på, hvordan de to intellektuelle og den gængse bruger agerer på Facebook, er imidlertid iøjnefaldende. Hvor selvrealisering, hygge og venskaber er i højsædet hos 
almindelige brugere, er begge beherskede i interessen for at udvikle horisontal imødekommenhed. I stedet bruges medieplatformen til at prikke til den enkeltes samvittighed. Bevidstgørelsen kan svinge fra det personlige (Brinkmanns bestandige kritik af forbrug $\mathrm{fx}$ ) over det politisk almene (begge kritiserer fx det menneskesyn, der dominerer dansk indvandrerpolitik), sprogkritik (Jensen) til vækstkulturens endeligt (Jensen).

Afslutningsvis vil jeg for at anskueliggøre og elaborere videre på det afvigende mht. brugen af Facebook hos de to public intellektuelle kort sammenstille med et par markante forskeres udlægninger af de sociale netværksmedier. Det digitale medium er ifølge Friedlander karakteriseret ved at være "pluralized, centerless, and disrupted" (Friedlander, 2008, p. 184). Den karakteristik matcher Facebook, men følgere af de to intellektuelle finder omvendt centrerede og analytiske udsagn om en verden, der nok ikke hænger sammen, men det er muligt at tænke over den. Der appelleres til følgerne, fordi der er behov for radikale forandringer. De to kan være pluralistiske i deres tilgang til mangt og meget, men opløste eller centrumløse er deres tekster langtfra.

I Gunn Enlis studie af den medierede autenticitetskultur fokuseres på tre netstrategier: spontanitet, immediacy og det ordinære (Enli, 2015). Alle er evidente i forhold til gængs praksis på Facebook. At fremstå som autentisk og transparent giver venner; at være spontan og uformel er tryghedsbefordrende. Konsensus og konformitet følges ad. Men de elitære intellektuelle vil netop ryste læseren ud af vante opfattelser af tilværelsen, og de vil være alt andet end spontane, for det refleksive og respekten for det refleksive er endnu et sine qua non. Deres tekster er heller ikke ligefrem transparente.

Facebook er af Manuel Castell blevet beskrevet som "masse-selv-kommunikation" (Hjarvard, 2018, p. 167). Studiet af de to 'public' intellektuelle markerer igen en afvigelse fra reglen. De intellektuelle vil per definition anfægte selvtilstrækkeligheden og forholder sig (derfor) til fælles anliggender, men på den anden side følger selvkommunikationen med, fordi en Facebook profil er stedet, der viser, hvor ombejlet man er.

Det umulige i et radikalt oprør mærkes også på de intellektuelles følgere. Det varmer at være en del af det fællesskab, som kritiserer konsensuskulturen. Der er mange motiver til at indgå i et holdningsfællesskab (Ellison, 2011; Papacharissi, 2011, 2015). Politisk orientering rummer også affektive motiver, men de lokale supportere forholder sig faktisk til samfundsmæssige konflikter, samtidig med at de indgår i en af tidens mange forestillede, uforpligtende fællesskaber.

De sociale mediers mange brugere har svært ved at se bort fra popularitetsparadigmet. Selv den mest inkarnerede intellektuelle opererer i en kultur, hvis ledetråd her formuleres af en af Marwicks informanter: "Everyone - EVERYONE - needs to start thinking of themselves as a brand. It is no longer an option; it is a necessity" (Marwick, 2013, p. 171; Khamis, 2016). Popularitetsorden tvinger de intellektuelle til at opfinde nye fremstillingsformer, der fanger de læserne. Det accentuerer det udfordrende i at forene kompleks tankegang med de dominerende korte og/ eller spontane former. Likability matcher heller ikke med den intellektuelles forpligtigelse til at tematisere samfundsmæssige konflikter. 
Popularitet implicerer konsensus, mens den intellektuelle tilstræber dissensus. På den anden side viser historien om Carsten Jensen og Svend Brinkmann, at en kontroversiel profil kan forenes med popularitet. Følgerne deler tydeligvis holdninger og ideologi med de intellektuelle.

Det frie markeds logik virker per automatik, når man tjekker, hvor mange likes en post har fået, og når man registrerer, hvor mange følgere profilen har. Hvis intellektuelle skal specialisere sig i korte tekster, der kan fange nettets mange hurtigere læsere, så ville JeanPaul Sartre ikke have en chance i dagens sociale mediekultur. Den positive udlægning vil derimod være, at en mediebevidst og kreativ omgang med fremstillingsformerne sikrer de intellektuelle en eksistensberettigelse - også på de sociale medier. Men de dage er talte, hvor deres autoritet er intakt og uanfægtet. Habermas' pointering af, hvordan ambivalens knytter sig til forbindelsen mellem de intellektuelle og de sociale medier er med denne analyse dokumenteret.

\section{Noter}

1 Tallene er fra 1. april 2018 og Berlingske har efter denne artikels færdiggørelse lukket diverse tilknyttede blogs.

2 Jeg har registreret og arkiveret materialet (via screen shot) og læsere med adgang til Facebook opfordres til med selvsyn at tjekke de to forfatteres opslag m.m.

3 Læseren opfordres til ved selvsyn at tjekke såvel Svend Brinkmann som Carsten Jensens opslag og fotos.

4 Efter færdiggørelsen af denne artikel har Carsten Jensen fjernet det omtalte præsentationsfoto

\section{Litteratur}

Adorno, T.W. (1958). Essayet som form, i Passage nr. 28/29. Aarhus Universitet.

Aubin. F. (2013). Intellectuals, the Public Sphere and Dissemination Strategies. I P. Thijssen, W. Weyns \& S.

Mels (red.), New Public Spheres. Recontextualizing the Intellectual. London: Routledge.

Baert, P. (2015). The Existentialist Moment. The Rise of Sartre as a Public Intellectual. Cambridge: Polity Press.

Baert, P. (m.fl.) (2013/2016). The Rise of Embedded Intellectual: New Forms of Public Engagement and Critique. I P. Thijssen, W. Weyns \& S. Mels (red.), New Public Spheres. Recontextualizing the Intellectual. London: Routledge.

Baert, P. \& Shipman, A. (2012). Transforming the Intellectual, I Baert, P (ed.): The Politics of Knowledge. London: Routledge.

Bruns, A. (2008). Blogs, Wikipedia, Second Life, and Beyond. From Production to Produsage. New York: Peter Lang.

Debray, R. (1979/1981). Teachers, Writers, Celebrities: The Intellectuals of Modern France. London: NLB.

Bourdieu, P. (1992). Texter om de intellektuelle. Stockholm: Brutus Östlings Bokförlag. 
Bové, P.A. (1986). Intellectuals in Power: A Genealogy of Critical Humanism. New York: Columbia University Press.

Brinkmann, S. (2008). Identitet. Udfordringer i forbrugersamfundet. Aarhus: Klim.

Brinkmann, S. (2014). Stå fast - et opgør med tidens udviklingstrang. København: Gyldendal

Brinkmann, S. (red. m.fl.) (2015). Diagnoser. Perspektiver, kritik og diskussion. Aarhus: Klim.

Brinkmann, S. (2016). Ståsteder. 10 gamle ideer til en ny verden. København: Gyldendal.

Brinkmann, S. (2017). Gå glip. Om begræensningens kunst I en græenseløs tid. København: Gyldendal.

Collini, S. (2006). Absent Minds. Intellectuals in Britain. Oxford: Oxford University Press.

Dahlgren, P. (2012). Public Intellectuals, Online Media, and Public Spheres: Current Realignment 95-110, New York: Springer.

Dahlgren, P. (2013). From Public to Civic Intellectuals: Political Agency and Emerging Media Landscapes. I

P. Thijssen, W. Weyns \& S. Mels (red.), New Public Spheres. Recontextualizing the Intellectual. London: Routledge.

Eco, U. (1964/1977). Apocalyptic and Integrated Intellectuals: Mass Communication and theories of Mass Culture, I Apocalypse Postponed. London: flamingo.

Ellison, N. (m. fl.) (2011). With a Little Help From My Friends. How Social Network Sites Affect Social Capital Processes. I Z. Papacharissi (red. m. f.), A Networked Self. Identity, Community, and Culture on Social Network Sites, London: Routledge.

Enli, G. (2015). Mediated Authenticity. How the Media Constructs Reality. Berlin: Peter Lang.

Eyerman, R. (1994). Between Culture and Politics: Intellectuals in Modern Society. Cambridge: Polity Press. Etzioni, A. (red. m. fl.) (2006). Public Intellectuals. An Endangered Species. Maryland: Rowman \& Littlefield. Friedlander, L. (2008). Narrative Strategies in a digital age: Authorship and authority. I K. Lundby (red.).

Digital Storytelling, Mediatized Stories. Self-representations in New Media. New York: Peter Lang.

Furedi, F. (2004). Where Have All the Intellectuals Gone? Confronting 21 ${ }^{\text {st }}$ Century Philistinism. London: Continuum.

Gramsci, A. (1929-35/1991). Føngselsoptegnelser I-II. København: Museum Tusculanums forlag.

Haarder, J.H. (2014). Performativ biografisme. En hovedstrømning i det senmodernes skandinaviske litteratur. København: Gyldendal.

Habermas, J. (2008/2009). An Avantgardistic Instinct for Relevances: The Role of the Intellectual and the European Cause, i Europe. The Faltering Project. Cambridge: Polity.

Hansen, N.G. (2013). Danske tidsånder 1940-2010. Fra Hal Koch og K.E. Løgstrup til Anders Fogh Rasmussen. København: Anis.

Hartley, J. (2008). Problems of expertise and scalability in self-made media. I K. Lundby (red.). Digital Storytelling, Mediatized Stories. Self-representations in New Media. New York: Peter Lang.

Hjarvard, S. (2018). Netværksmediernes sociologi. I P.S. Lauridsen \& E. Svendsen (red.), Medieteori. København: Samfundslitteratur.

Illouz, E. (2007). Cold Intimacies. The Making of Emotional Capitalism. Cambridge: Polity.

Jacoby, R. (1987). The Last Intellectuals: American Culture in the Age of Academy. New York: Basic. Jennings, J. (red.) (1997). Intellectuals in Politics, from Dreyfus affair to Salman Rushdie. London: Routledge. Jenkins, H. (2006). Converge Culture. Where Old and New Media Collide. London: New York University Press.

Jensen, C. (2018). Køeldermennesker. Om populisme og besvœret med at væere menneske. København: Politikens Forlag.

Jensen, J.L. (red. m.fl.) (2013). Facebook. Fra socialt netvcerk til metamedie. Frederiksberg: Samfundslitteratur. 
Jensen, J.L. (2013). Facebook som politisk offentlighed. I J.L. Jensen (red. m.fl.), Facebook. Fra socialt netvæerk til metamedie. Frederiksberg: Samfundslitteratur.

Jørgensen, D. (2002). Viden og visdom. Spørgsmålet om de intellektuelle. Frederiksberg: Det lille forlag. Khamis, S., L. Ang \& Welling, R. (2016). Self-branding, 'microcelebrity' and the rise of social Media Influencers, Celebrity Studies, 8:2, 191-208.

Klastrup, L. (2016). Sociale netvarksmedier. Frederiksberg: Samfundslitteratur.

Kierkegaard, S. (1846/ 1982). Afsluttede uvidenskabelig Efterskrift. Første halubind. København: Gyldendal. Kock, C. (2018). Perfide ordgyderier fra elfenbenstårnet. På Kommunikationsforum. 08-02-2018.

Lambert, A. (2013). Intimacy and Friendship on Facebook. Hampshire: Palgrave Macmillan.

Larsen, M.C. (2013). Unges identitetsdannelse på Facebook. I J.L. Jensen (red. m.fl.), Facebook. Fra socialt netvaerk til metamedie. Frederiksberg: Samfundslitteratur.

Lundby, K. (red.) (2008). Digital Storytelling, Mediatized Stories. Self-representations in New Media. New York: Peter Lang.

Mannheim, K. (1929/2015). Ideology and Utopia. London: Forgotten Books.

Marshall, P.D. (2010). The Promotion and Presentation of the Self: Celebrity as Marker of Presentational Media, Celebrity Studies, 1.

Marwick, A. E. (2013). Status Update. Celebrity, Publicity \& Branding in the Social Media Age. London: Yale University Press.

Mendelson, A.L. (m.fl.) Look At Us. Collective Narcissism in College student Facebook Photo Galleries, i Papacharissi 2011.

Melzer, A.M. (2003). What Is an Intellectual?, i Melzer, A. M. (red. m.fl.): The Public Intellectual. Between Philosophy and Politics. Oxford: Rowman \& Littlefield Publishers, Inc.

Mercier, S. (2018). De digitale intellektuelles ansvar. Specialeafhandling, primo 2018, RUC.

Misztal, B.A. (2007). Intellectuals and the Public Good. Creativity and Civil Courage. Cambridge: Cambridge University Press.

Moi, T. (2008/2014). Simone de Beauvoir. The Making of an Intellectual Woman. Oxford: Oxford University Press.

Müller, J.-W. (2000). Another Country. German Intellectuals, Unification and National Identity. London: Yale University Press.

Müller, J.-W. (2016). Hvad er populisme? København: Informations forlag.

Papacharissi, Z. (red. m. fl.) (2011). A Networked Self. Identity, Community, and Culture on Social Network Sites, London: Routledge.

Papacharissi, Z. (2015). Affective Publics. Sentiment, Technology, and Politics. Oxford: Oxford University Press.

Posner, R. (2003). Public Intellectuals: A Study in Decline. Cambridge: Harvard University Press.

Rettberg, J.W. (2014). Blogging. Digital media and Society Series. Cambridge: Polity.

Rettberg, J.W. (2014). Seeing Ourselves Through Technology: How We Use Selfies, Blogs and Wearable devices to See and Shape Ourselves. Hampshire: Palgrave Macmillan.

Said, E. (1994/1996). Den intellektuelles ansvar. Reith forelæesninger 1993. København: Gyldendal.

Sand, S. (2016/2918). The End of the French Intellectual. London: Verso.

Sartre, J.-P. (1972/1979). Forsvar for de intellektuelle. København: Bibliotek Rhodos.

Svendsen, E. (2016). De integrerede intellektuelle, Kultur \& Klasse nr. 122.

Sørensen, A.S. (2013). Facebook - kommunikation for kommunikationens skyld? I J.L. Jensen (red. m.fl.),

Facebook. Fra socialt netvark til metamedie. Frederiksberg: Samfundslitteratur.

Sørensen, V. (1959/1973). Digtere og daemoner. Fortolkninger og vurderinger. København: Gyldendal. 
Article: Danske intellektuelle på Facebook

Thijssen, P. (red. m.fl.) (2013/2016). New Public Spheres. Recontextualizing The Intellectual. London:

Routledge.

Taplin, J. (2017). Move Fast and Break Things. København: Jyllands-Postens forlag.

Thing, M. (1993). Kommunismens kultur. DKP og de intellektuelle 1918-1960. I-II. København: Tiderne skifter.

Turner, G. (2010). Ordinary People and the Media. The demotic Turn. London: Sage.

Turner, F. \& Larson, C. (2015). Network celebrity: Entrepreneurship and the new public intellectuals, Public Culture, 27, 53-84.

Woolf, V. (1928/1978). Eget vøerelse. København: Samlerens billigbøger.

Erik Suendsen

Lektor

Institut for Kommunikation og Humanistisk Videnskab

Roskilde Universitet

evs@ruc.dk 